\title{
Urinary incontinence in a community sample of older adults: prevalence and impact on quality of life
}

\author{
JANE SIMS ${ }^{1}$, COLETTE BROWNING ${ }^{1}$, BIRGITTA LUNDGREN-LINDQUIST ${ }^{2} \&$ \\ HAL KENDIG ${ }^{3}$ \\ ${ }^{1}$ School of Primary Health Care, Monash University, Melbourne, Australia, ${ }^{2}$ Faculty of Health Sciences, fönköping \\ University, Fönköping, Sweden, and ${ }^{3}$ Faculty of Health Sciences, University of Sydney, Sydney, Australia
}

Accepted October 2010

\begin{abstract}
Purpose. To measure the prevalence of urinary incontinence (UI) in a community-dwelling sample and the impact of selfreported UI on well-being and activity in older men and women.

Method. Participants were older adults aged $\geq 65$ years. Measures included the frequency of urgency incontinence, depression, positive and negative affect and social activity, independence in activities of daily living (IADL) and self-rated health. The data were collected by face to face interview (1994) and computer assisted telephone interviews (1996).

Results. Of the 796 participants, $28 \%$ experienced urgency incontinence and $21 \%$ reported stress incontinence occasionally or often, with higher rates among women. The threshold for the impact on depression, negative affect and IADL was with occasional occurrence of urinary urgency incontinence. For positive affect and self-rated health, the threshold was experiencing urinary urgency incontinence often. The presence of urinary stress incontinence was associated with depression, IADL dependence, self-rated health and positive affect. Overall, women with incontinence had higher negative affect scores, but men with stress incontinence had higher scores than those without.

Conclusions. The impact of incontinence highlights the need for more effective management of the condition. The threshold for the effects of urinary urgency incontinence on mental health and functionality is lower than for the effects on general health. There is a need to consider how older people judge the impact of UI in the design of targeted health promotion programmes.
\end{abstract}

Keywords: Incontinence, elderly, quality of life, IADL

\section{Introduction}

Urinary incontinence (UI), the involuntary loss of urine, has been identified as a significant health problem for older people, especially women [1-4]. Current figures indicate that UI affects 4 million Australians [1]. It is not a normal part of the ageing process, but the prevalence of urgency and mixed incontinence increases significantly with age [5]. UI places a burden on the individual, their caregivers and society. UI is a common reason for admission to residential care accommodation [6]. United States (US) figures produced over a decade ago estimated the economic impact of incontinence in older people at $\$ 26.3$ billion, or $\$ 3565$ per person [7], without wholly accounting for the indirect costs due to factors such as urinary tract and skin infections and falls. With an ageing population, these figures are set to increase further.

As the following section illustrates, studies of the prevalence of UI in community dwelling adults have yielded varied estimates, attributable to the types of populations under study and the measurement protocols used: the criteria used to classify the presence of UI, whether severity of symptoms is measured and whether the measures used are subjective or objective [8,9]. The current study provides an estimate of the prevalence of urinary urgency and stress incontinence in a representative community sample of older Australians.

Correspondence: Dr. Jane Sims, Faculty of Medicine, Nursing and Health Sciences, Monash University, Bdg 1, 270 Ferntree Gully Road, Notting Hill, Victoria 3168, Australia. Tel: +61-3-9902 4514. Fax: +61-3-8575-2233. E-mail: jane.sims@monash.edu 


\section{Prevalence}

Urgency incontinence is the most common incontinence type in older people. In the US, Nygaard and Lemke reported prevalence rates of $36 \%$ and $40 \%$ for urgency and stress incontinence respectively in rural women aged 65 and over [10]. In another US study, Roberts et al. sampled men and women aged 50 and reported prevalence rates of UI of $24 \%$ for men and $49 \%$ for women [5]. These rates include both stress and urgency incontinence and participants were further classified according to severity, based on frequency of occurrence and amount leaked. About three-quarters of those who were incontinent were classified as exhibiting mild UI symptoms and women $(30 \%)$ were more likely than men $(22 \%)$ to be classified as having moderate or severe UI.

A range of prevalence rates has been reported in various Swedish population studies. Molander et al. surveyed a random sample of women aged 65-84 years, selected from the National Population Register [11]. Prevalence rates of UI (non-specific) increased with age from $14 \%$ in those aged $60-64$ years to $25 \%$ in those aged 80 years and over. In Australia, estimates of prevalence rates have been unreliable [12]. Chiarelli and Brown published the baseline self-reported prevalence rates of leaking urine 'rarely', 'sometimes' or 'often' in the past 12 months in a large-scale cohort study, the Australian Longitudinal Study of Women's Health (ALSWH), of women aged 18-23, 45-50 and 70-75 years. Rates were $12.8,36.1$ and $35 \%$, respectively in each of the age groups [13]. The majority were still experiencing problems 3 years later [14]. Compared to younger women, almost a third $(28.2 \%)$ of older women were classified with severe incontinence. Whilst mixed incontinence was most common, older women were more likely to report urge incontinence $(6.2 \%)$. This research focused upon those with a history of incontinence; the relative risk of health impairment was not assessed.

\section{The impact of incontinence on well-being}

Incontinence or even overactive bladder (OAB) dry can negatively influence a person's social and physical activities [15], although studies of the impact of UI on quality of life have yielded mixed results. Studies concerning the impact of UI on quality of life in community dwelling adults have yielded differing results. As with prevalence studies, the differences in outcomes of these studies are also related to sample type and to the measures used to classify UI and determine the impact of UI on quality of life. For example, some studies have measured general quality of life, whereas others have used continence specific measures of quality of life. The relative sensitivity of the measurement tools also contributes to the observed variations in UI's impact across studies. One way to explain and to address these variations in results is to consider the threshold of severity of symptoms necessary to impact on various aspects of well-being.

The influence of threshold effects and sample characteristics on the perceived impact of various problems with activities of daily living (ADL) was evident in a study by Philp et al. [16]. They asked health care experts, fit older people, disabled older people and carers to weight ADL according to how badly off a person would be if $\mathrm{s} / \mathrm{he}$ was unable to perform the activity. The scores varied considerably between the four groups of participants. For both 'occasional-' and 'frequent-' 'bladder accidents', health professionals judged bladder accidents as more serious than did disabled older people, followed by carers and fit older people. Health professionals scored frequent bladder accidents as almost twice as serious as did carers and older people.

A number of studies have investigated the impact of UI on general health outcomes such as self-rated health, functional independence, psychological wellbeing and quality of life [17-22]. Herzog, Fultz, Brock, Brown and Diokno investigated the relationship between UI and psychological distress in men and women aged 60 years and over living in the community [19]. Severity of UI was measured according to frequency and amount. Participants were asked about urine loss of any amount in the past 12 months. For the whole sample, UI did not influence positive affect and happiness and there was no relationship between UI and activity level, feelings of control and old age identification. For the women in the sample, depression and negative affect scores increased and life satisfaction scores decreased with increasing severity of UI. For men, the influence of UI on well-being was less systematic. In men, those with mild UI (1-9 days in past year and/or $<1 / 2$ teaspoon/day on $<300$ days in past year) had significantly poorer negative affect and depression scores compared to the continent group [19]. The effects of UI on depression, mood (negative affect) and life satisfaction were mediated by general health status. Those with UI were less healthy than those participants who were continent.

Grimby et al. assessed the impact of stress and urgency incontinence on quality of life in women aged 65-84 years using the generic Nottingham Health Profile (NHP) questionnaire [21]. Women with urge and mixed UI scored higher than continent women on the subscales of emotional disturbances. Women with all types of UI were more socially isolated than continent women. 
In a qualitative study of the impact of urgency incontinence on quality of life, DuBeau et al. found that experts and patients hold different views about the impact of UI on quality of life [20]. Participants were asked to describe the experience of incontinence and what aspects of daily life were affected. Experts tended to focus on the impact of UI on functional capacity while patients were more concerned about the impact of UI on psychological wellbeing and interference with activities.

The impact of UI on quality of life has also been confirmed by intervention studies. Fonda et al. [22] conducted an intervention for older people attending a continence clinic who included bladder retraining, pelvic floor exercises and general advice about fluid intake. Ninety-eight per cent of the intervention group reported cured or improved symptoms at 4month follow-up [22].

In summary, the impact of UI on quality of life and well-being is variable $[19,21]$ and may be mediated by general health status. The impact of UI does not always lead to reductions in daily activities or social interaction [23,24], despite the observation by DuBeau et al. that patients were most concerned about the impact of urgency UI on well-being and participation in activities [20]. Few studies have investigated the relationship between symptom severity and quality of life using a range of indicators.

The aim of this study was to investigate the impact of urgency and stress incontinence on a range of indicators of quality of life including psychological well-being and social activity. For urgency incontinence, the impact of the severity of UI was examined (as measured by frequency of occurrence) on various domains of quality of life was examined in order to determine if there are different threshold effects for the impact of UI on quality of life. For stress incontinence, the impact of the presence of symptoms on quality of life was assessed. The study also investigated whether UI has different impacts on quality of life for women compared to men. The current article focuses on cross-sectional data from one wave (1996) of an ongoing longitudinal study. The continence prevalence rates over the course of the study will be presented in a separate article.

\section{Methods}

\section{Sample details}

The MELSHA study is a longitudinal study of 1000 persons aged 65 years and over living in noninstitutional settings in Melbourne, Victoria, Australia [25]. Details of the cohort's recruitment and profile can be found elsewhere [26].

\section{Study tools and methods}

Face-to-face interviews were conducted by trained interviewers in respondents' homes on a rolling basis from May 1994 to December 1994 using a structured recording tool and questionnaire; at the initial data collection in 1994 participants also filled in a self-completion questionnaire. At the end of the interview, interviewers conducted a brief physical examination and the self-completion questionnaire was left for later return by mail. A short structured interview was used for people who were unable to complete the full interview or when a proxy was needed. In 2004, participants were also interviewed face to face using a structured questionnaire in their homes. During the intervening period, between 1994 and 2004, every 2 years $(1996,1998,2000,2002)$ participants were interviewed using a Computer Assisted Telephone Interviewing method (CATI). In 1995, 1997, 1999, 2001 and 2005 participants completed a mail-out questionnaire. Over the period of the study, final outcomes data have been collected for the 1000 participants. The current article focuses upon data gathered in the second data collection round in 1996, when questions about both urgency and stress incontinence were included.

The major measures collected in the study included a comprehensive battery of measures of medical conditions, functional and social health, health behaviours, mental health, pain, falls, continence, medication use, caregiving, spirituality, sexuality, neighbourhood satisfaction and health and community service use. The full interview schedule is reported elsewhere [25].

\section{Measures}

\section{Incontinence questions}

All participants were asked if they had ever accidentally passed urine in 1994 and 2004, the two major data collection waves. The question was not asked in 1996 , so the ability to determine urgency incontinence in terms of OAB (wet) versus OAB (dry) was compromised. In 1996, the following question was used to determine urgency, 'Have you ever had difficulty holding your urine until you get to the toilet?' (responses were often, occasionally, never). This item was adapted from measures of incontinence in contemporary use in the older Americans Resources and Services Instrument [27]. For those who answered 'often' or 'occasionally' the following questions were asked: 'Do you think problems controlling your bladder have made you cut down on any activities?' (yes or no) and 'At what age did you first start experiencing urinary incontinence?' To 
determine stress incontinence, participants were asked 'Do you ever leak urine when you cough, sneeze or laugh?' (yes or no). No measure of severity of stress incontinence was obtained.

\section{Domains of quality of life}

A number of measures of quality of life were included as outcome measures. These included depression, happiness, positive and negative affect, social activity, independence in instrumental ADL and self-rated health.

(1) Depressive symptoms. The Depression Scale from the Psychogeriatric Assessment Scales (PAS) was used to measure depression [28]. This subscale comprises 12 items. The internal reliability of the subscale was 0.67 . Eighty per cent of the sample scored $\leq 2$ and $7 \%$ scored 5 or more. This profile is very similar to that previously reported [28]. A participant was classified as depressed if they scored 3 or more.

(2) Positive and negative affect. The Philadelphia Geriatric Centre Affect Scale (PGCAS) was used to assess mood [29]. Each subscale consisted of 5 items and the internal reliability of both scales was 0.74 . To measure positive affect the participants were asked how often they felt: happy, interested, energetic, content and warm-hearted. To measure negative affect the participants were asked how often they felt: sad, annoyed, worried, irritated and depressed. Scores for both subscales ranged from 5 to 25 , with a higher score indicating greater demonstration of the mood state.

(3) Social activity: Interaction with family and friends. A 6-item social interaction index based on measures used in the British Health and Lifestyle Survey [30] and in the Multilevel Assessment Instrument [31] was used to measure social activity. Participants were asked how often during the past 2 weeks they had personal or telephone contact with family and/or friends. The family interaction score $(\alpha=0.67)$ ranged from 0 to 18 and the friends interaction score $(\alpha=0.69)$ ranged from 0 to 18. Overall social interaction score was the sum of these indices, ranging from 0 to 36 , with a higher score indicating greater interaction.

(4) Instrumental Activities of Daily Living (IADL). The need for assistance with IADL was measured using the Multilevel Assessment Instrument developed by the Philadel- phia Geriatric Centre [31]. Respondents were asked if they needed help performing each IADL (shopping, gardening, housework, cooking). They were rated dependent if they needed help with one or more of these tasks.

(5) Self-rated health. Participants were asked to rate their health - as compared to other people their age - as excellent, very, good, good, fair or poor. Scores ranged from 0 to 5, with a higher score indicating poorer health.

\section{Data analysis}

Firstly, the prevalence of urgency and stress UI for men and women and different age groups were determined. Secondly, the impact of severity of symptoms (as measured by frequency of occurrence of urgency incontinence) on quality of life was examined to determine whether and if so, at what threshold, urinary urgency incontinence diminished quality of life. Thirdly, we examined whether there were gender differences in the impact of urgency and stress UI on quality of life.

The amount of social activity, self-rated health, positive affect and negative affect were treated as continuous normally distributed variables. The relationship between UI and quality of life was examined using two-way ANOVA for each measure of quality of life separately. A number of measures showed skewed distribution and for these nonparametric analyses were conducted. Depression was categorised as 'not depressed', 'borderline depression' and 'depressed' and IADL scores were dichotomised as 'needs help' and 'does not need help'. Thus Kruskall-Wallis analyses by ranks and Mann-Whitney $U$ post-hoc comparison of ranks were used to determine the impact of urgency and stress incontinence frequency on the depression and the IADL measures for the full sample. A two-way ANOVA was conducted to explore the impact of stress incontinence and gender on continuous measures of quality of life. Subjects were categorised as stress continent or not, according to their response to the item (yes or no). For the depression and IADL scores, Chi-square analyses were conducted for each gender.

\section{Results}

\section{Prevalence}

Seven hundred ninety-six people answered the question on urgency incontinency. Just over a quarter $(28 \%)$ had difficulty holding urine until they 
got to the toilet 'often' (6\%) or 'occasionally' (22\%). One-fifth $(21 \%)$ of respondents reported stress incontinence symptoms. A small minority of respondents $(10.4 \%)$ reported experiencing both types of incontinence.

As shown in Table I, women were more likely to report urgency incontinence (often or occasionally) than were men $(32 \%$ versus $22 \%$ respectively; $\left.\chi^{2}=10.1, p<0.01\right)$. With regard to more severe incontinence, older men showed slightly higher prevalence rates than younger men and younger women than older women, but there was no significant main effect for age.

Significantly more women than men reported stress incontinence $\left(32.6 \%\right.$ vs. $7.0 \%, \chi^{2}=78.4$, $p<0.001)$. Older men showed slightly higher prevalence rates than younger men $(6.8 \%$ vs. $7.7 \%)$, whereas older women had slightly lower prevalence than younger women ( $34.6 \%$ vs. $28.5 \%)$ but these differences were not statistically significant (Table I).

\section{Urgency incontinence}

The presence of urgency incontinence was positively associated with depression $\left(\chi^{2}=32.67, p<0.001\right)$ and needing help with ADL $\left(\chi^{2}=35.85, p<0.001\right)$ (Table II). Comparison of ranks indicated that for depression there was a significant difference between never and often experiencing urgency incontinence and between never and occasionally experiencing urgency incontinence. Thus, the threshold for an increased likelihood of depression was the onset of occasional urgency incontinence. There was also a significant difference between occasionally and often experiencing urgency incontinence, indicating that experiencing urgency incontinence often was more likely to be associated with depressive status compared to experiencing it occasionally. For IADL, comparison of ranks indicated a significant difference between never and often experiencing urgency incontinence and between never and occasionally experiencing urgency incontinence. Thus for IADL the threshold for the impact of urgency incontinence was experiencing UI occasionally. Further, there was a significant difference between occasionally and often experiencing UI, indicating that experiencing urgency incontinence often was more likely to be associated with dependence compared to occasionally experiencing incontinence.

Table II shows the mean scores for self-rated health, positive and negative affect and amount of interaction with family and friends for each level of severity of urgency incontinence. ANOVA and posthoc comparisons were used to test the impact of urgency incontinence on each of these domains of quality of life. Urgency incontinence had a significant main effect on self-rated health $\left(F_{(2,769)}=11.29\right.$, $p<0.001)$ and the differences occurred between never and often experiencing incontinence and between occasionally and often experiencing incontinence. Therefore, the threshold for urgency incontinence impacting on self-rated health was experiencing incontinence often. The significant difference between occasionally and often experiencing incontinence indicates that greater severity was associated with poorer health. Urgency incontinence had a significant main effect on negative affect ( $F$ $(2,769)=8.79, p<0.001)$ and the differences occurred between often and never experiencing incontinence and between occasionally and never experiencing incontinence, but not between often and occasional occurrence. The threshold for urgency incontinence impacting on negative affect was occasional occurrence. Urgency incontinence had a significant main effect on positive affect $\left(\mathrm{F}_{(2,769)}=5.84, p<0.01\right)$ and the differences occurred between often and never experiencing incontinence. The threshold for urgency incontinence impacting on positive affect was experiencing incontinence often. Urgency incontinence had no significant impact on the amount of interaction with family or friends.

Table III shows the impact of urgency incontinence on depression and the measures of IADL dependence for men and women. The presence of urgency incontinence was positively associated with depression in women $\left(\chi^{2}=13.8, p=<0.01\right)$ but not men. Urgency incontinence was positively associated with needing help with ADL in both women and

Table I. The prevalence of urgency and stress incontinence by age group and gender.

\begin{tabular}{|c|c|c|c|c|c|c|c|}
\hline \multirow[b]{2}{*}{ Gender } & \multirow[b]{2}{*}{ Age group (years) } & \multicolumn{3}{|c|}{ Urgency: difficulty holding urine until get to the toilet } & \multicolumn{3}{|c|}{$\begin{array}{c}\text { Stress: ever leak urine when you cough, } \\
\text { sneeze or laugh? }\end{array}$} \\
\hline & & Often, $n(\%)$ & Occasionally, $n(\%)$ & Never, $n(\%)$ & Yes, $n(\%)$ & No, $n(\%)$ & Total, $n$ \\
\hline \multirow[t]{2}{*}{ Male } & $65-74$ & $8(3.0)$ & $48(18.1)$ & $209(78.9)$ & $18(6.8)$ & $247(93.2)$ & 265 \\
\hline & $75+$ & $9(8.7)$ & $17(16.3)$ & $78(75.0)$ & $8(7.7)$ & $96(92.3)$ & 104 \\
\hline \multirow[t]{2}{*}{ Female } & $65-74$ & $23(8.1)$ & $66(23.3)$ & $194(68.6)$ & $98(34.6)$ & $185(65.4)$ & 283 \\
\hline & $75+$ & $5(3.5)$ & $44(30.6)$ & $95(66.0)$ & $41(28.5)$ & $103(71.5)$ & 144 \\
\hline
\end{tabular}


Table II. Depression, IADL dependency, self-rated health, positive and negative affect, interaction with friends and family by urinary urgency incontinence severity.

\begin{tabular}{|c|c|c|c|}
\hline & \multicolumn{3}{|c|}{ Urinary urgency incontinence } \\
\hline & $\begin{array}{c}\text { Never } \\
(n=576)\end{array}$ & $\begin{array}{c}\text { Occasionally } \\
(n=175)\end{array}$ & $\begin{array}{l}\text { Often } \\
(n=45)\end{array}$ \\
\hline Depressed (\%) & 8.7 & 14.9 & $24.5^{\mathrm{a}}$ \\
\hline Need help (\%) & 14.9 & 24.6 & $48.9^{\mathrm{b}}$ \\
\hline $\begin{array}{l}\text { Self-rated health, } \\
\text { mean (SD) }\end{array}$ & $2.4(1.0)$ & $2.6(0.9)$ & $3.1(1.1)^{\mathrm{a}}$ \\
\hline $\begin{array}{l}\text { Positive affect, } \\
\text { mean (SD) }\end{array}$ & $20.4(3.0)$ & $19.8(3.1)$ & $19.0(3.1)^{\mathrm{a}}$ \\
\hline $\begin{array}{l}\text { Negative affect, } \\
\text { mean (SD) }\end{array}$ & $10.6(3.4)$ & $11.5(3.3)$ & $12.8(4.1)^{\mathrm{b}}$ \\
\hline $\begin{array}{l}\text { Friends contact, } \\
\text { mean (SD) }\end{array}$ & $12.2(3.1)$ & $12.2(3.3)$ & $12.0(4.0)^{\mathrm{C}}$ \\
\hline $\begin{array}{l}\text { Family contact, } \\
\text { mean (SD) }\end{array}$ & $11.1(3.1)$ & $10.9(3.1)$ & $11.8(3.6)^{\mathrm{c}}$ \\
\hline
\end{tabular}

Depression was measured using the Psychogeriatric Assessment Scale.

${ }^{\mathrm{a}} p<0.01,{ }^{\mathrm{b}} p<0.001,{ }^{\mathrm{c}}$ not significant.

Table III. Depression measured by Psychogeriatric Assessment Scale and IADL dependence by urinary urgency incontinence status and gender.

\begin{tabular}{lccc}
\hline & \multicolumn{3}{c}{ Urinary incontinence } \\
\cline { 2 - 4 } Gender & Never & Occasionally & Often \\
\hline Male, $n=369$ & & & \\
Depressed (\%) & 7.7 & 10.8 & 11.8 \\
Need help (\%) & 9.1 & 13.8 & $47.1^{\mathrm{a}}$ \\
Female, $n=427$ & & & \\
Depressed (\%) & 9.7 & 17.3 & $32.1^{\mathrm{b}}$ \\
Need help (\%) & 20.8 & 30.9 & $50.0^{\mathrm{b}}$ \\
\hline${ }^{\mathrm{a}} p<0.001,{ }^{\mathrm{b}} p<0.01$. & & &
\end{tabular}

men (women $\chi^{2}=14.0, p<0.01 ;$ men $\chi^{2}=22.8$, $p<0.001)$. With regard to the impact of urgency incontinence on self-rated health, negative and positive affect and amount of interaction with friends and family, there was a main effect of gender on negative affect $\left(F_{(1,769)}=15.86, p<0.001\right)$ with poorer (higher) scores in women, but there was no significant continence by gender interaction effect (data not shown). There was no significant main effect of gender on the other quality of life variables.

\section{Stress incontinence}

For stress incontinence, a threshold effect could not be explored as the respondents were only required to answer 'yes' or 'no' regarding the occurrence of stress incontinence. The impact on quality of life was therefore assessed relative to those without the condition. Table IV shows the impact of stress
Table IV. Stress incontinence by IADL, depressive status, selfrated health, positive and negative affect and interaction with friends and family.

\begin{tabular}{|c|c|c|}
\hline & \multicolumn{2}{|c|}{ Urinary incontinence } \\
\hline & No $(n=631)$ & Yes $(n=165)$ \\
\hline IADL independent & $527(83.5 \%)$ & $118(71.5 \%)$ \\
\hline IADL dependent & $104(16.5 \%)$ & $47(28.5 \%)^{\mathrm{a}}$ \\
\hline Not depressed & $575(91.1 \%)$ & $134(81.2 \%)$ \\
\hline Borderline depressed & $42(6.7 \%)$ & $23(13.9 \%)$ \\
\hline Depressed & $14(2.2 \%)$ & $8(4.8 \%)^{\mathrm{a}}$ \\
\hline $\begin{array}{l}\text { Self-rated health, } \\
\text { mean }(95 \% \mathrm{CI})\end{array}$ & $2.45(2.37,2.53)$ & $2.72(2.57,2.87)^{\mathrm{a}}$ \\
\hline $\begin{array}{l}\text { Positive affect, } \\
\text { mean }(95 \% \mathrm{CI})\end{array}$ & $20.2(20.0,20.5)$ & $19.7(19.2,20.1)^{\mathrm{b}}$ \\
\hline $\begin{array}{l}\text { Negative affect, } \\
\text { mean }(95 \% \mathrm{CI})\end{array}$ & $10.7(10.5,11.0)$ & $11.6(11.1,12.2)^{\mathrm{c}}$ \\
\hline $\begin{array}{l}\text { Friends interaction, } \\
\text { mean }(95 \% \mathrm{CI})\end{array}$ & $12.312 .0,12.5)$ & $11.9(11.4,12.4)^{\mathrm{d}}$ \\
\hline $\begin{array}{c}\text { Family interaction, } \\
\text { mean }(95 \% \mathrm{CI})\end{array}$ & $11.2(10.9,11.4)$ & $10.9(10.5,11.4)^{\mathrm{d}}$ \\
\hline
\end{tabular}

incontinence on the quality of life measures. Incontinence was more prevalent amongst those with depressive symptoms $\left(\chi^{2}=13.21, p<0.001\right)$ and those who needed assistance with ADL $\left(\chi^{2}=12.26\right.$, $p<0.001)$. Stress incontinence had a significant main effect on self-rated health $\left(\mathrm{F}_{(1,771)}=17.11\right.$, $p<0.001)$ and positive affect $\left(\mathrm{F}_{(1,771)}=5.12\right.$, $p<0.05)$, but not on social interactions (Table IV). There was a significant continence by gender interaction effect on self-rated health $\left(\mathrm{F}_{(1,771)}=7.90, p<0.01\right)$, with men reporting stress incontinence having poorer scores than the women (men mean 3.2, SD 0.89; women mean 2.64, SD 0.98) (data not shown).

\section{Discussion}

The current study investigated the prevalence of UI in a representative community sample of older men and women and the impact of UI on domains of quality of life and health status.

\section{Prevalence}

The prevalence of UI in this sample was similar to estimates from other studies. The overall prevalence rates for urgency and stress incontinence were relatively high $(28 \%$ and $21 \%$ for urgency and stress incontinence respectively), with women showing significantly higher rates than men, particularly for stress incontinence. These rates are broadly consistent with those found in other studies such as 
Nygaard and Lemke [10] but higher than those reported by Thomas et al. [32] and Molander et al. [11]. The variability in the published rates from different studies may reflect cultural differences in propensity to report UI, differing sampling frames or may be related to the measurement techniques used in different studies. In the present study, we used a self-report measure which has been used widely in surveys and followed the recommendations of Fultz and Herzog to maximise data quality [9]. Nygaard and Lemke used the same self-report measure as used in the present study [10] whereas Molander et al. used a self-report measure validated against a 48-h pad test, micturition lists and a cough provocation test [11].

The greater prevalence of incontinence amongst women is reflective of the literature. For example, the Australian Longitudinal Study of Women's Health (ALSWH) examined incontinence histories amongst women of different ages. The prevalence rate amongst their oldest cohort (70-75 years) was $35 \%$ at baseline [14], similar to that in our study.

\section{Quality of life}

There was a main effect of urgency incontinence on mental health (depression, positive and negative affect), IADL and self-rated health, but not on social interaction. Studies of the impact of UI on quality of life and activity in older people have revealed inconsistent results. Herzog et al. also found mild effects of UI (non-specific) on depression and negative affect, but no effects on positive affect, happiness or activity level [19]. Hunskaar and Vinsnes [4] reported only moderately poor scores on the Sickness Impact Profile (which measures functional and emotional dysfunction) in women attending an incontinence clinic with urgency and stress UI, although scores were worse in those with more severe symptoms. Roberts et al. in a study of men with UI (non-specific) found significant impacts on quality of life measured in terms of dissatisfaction with spending the rest of their lives with a urinary condition [5]. Grimby et al. found that women with urgency or mixed UI were more likely to score high on the dimensions of emotional disturbance and social isolation than continent women [21]. Other studies have found that UI may not impact negatively on all aspects of daily activities or social interaction $[23,24]$. These conflicting results may be related to the threshold at which UI impacts on quality of life: our findings support this conclusion.

Individuals may need to experience a certain level of symptom severity before it impacts on their life. This threshold may vary depending on the way quality of life is measured. Affective measures such as mood and life satisfaction may be more influenced at lower thresholds of symptoms whereby individuals may perceive the onset of symptoms as a negative sign of the ageing process. While mild symptoms may not interfere with daily activity levels, more severe symptoms may have a greater impact on a person's ability to live a social and independent life. Hence quality of life measures related to functional independence may show strong relationships with the more severe levels of urinary symptoms. Indeed, we found evidence of an association with functional dependency even with the occasional experience of urgency incontinence. In a qualitative study of the impact of urgency incontinence on quality of life, DuBeau et al. found that experts and patients hold different views about the impact of urgency UI on quality of life [20]. Experts tended to focus on the impact of UI on functional capacity while patients are more concerned about the impact of UI on psychological well-being and interference with activities. The impact of UI on quality of life may show a U-shaped function with severity of symptoms. The impact may be high at the onset of symptoms, may reduce over time as the person adapts to the situation, but may increase again if the severity of symptoms increase. Roberts et al. [5] found that men with mild urinary symptoms were more likely to report dissatisfaction with the possibility that their urinary symptoms remained with them for the rest of their lives than those with moderate or severe urinary symptoms. This finding suggests that those men with more severe symptoms had adapted to their condition. The cross-sectional nature of the current data does not permit examination of symptom chronicity; this will be the focus of a further paper.

The present study found that the threshold at which UI impacted on quality of life varied between different measures of quality of life. Occasional urgency UI impacted significantly on depression and negative affect and IADL and the impact was greater in those who experienced urgency UI often. Experiencing urgency UI often impacted on selfrated health and positive affect whereas occasional urgency UI did not impact negatively on these measures of quality of life. Interactions with family and friends were not affected by UI. Measures of quality of life that tap negative mood appear to be affected at lower thresholds of urgency UI severity compared with measures which tap health status and social activity. This finding is consistent with the findings of Wyman et al. who found that the impact of UI was not consistent across all activities [24]. Herzog et al. found that for the women in their sample depression and negative affect scores increased with increasing symptom severity while activity levels were not affected by the presence of UI [19]. Herzog et al. note that some of the 
association between incontinence and mental health is attributable to underlying poor health. This argument adds weight to the need to address older people's comorbidities holistically in order to promote optimal quality of life.

We found that urinary urgency incontinence was associated with IADL dependence for both women and men. Both urgency and stress incontinence were associated with higher depression scores for women. The sample in general obtained relatively highpositive affect scores and low-negative affect scores but significant differences emerged between the incontinent and continent groups. Few studies have examined gender differences in the impact of UI on quality of life and our study suggests that the impact on mood is to lower the 'highs' in men and increase the 'lows' in women. The men reported lower selfrated health scores if they were stress incontinent sufferers as compared to continent men. Johnson et al. found a significant relationship between selfrated health and UI (undifferentiated) after adjustment for age, comorbidity and frailty in communitydwelling adults [33]. The relationship became insignificant if participants had IADL impairment.

In order to strengthen conclusions about these relationships it is necessary to examine longitudinal changes in UI and changes in quality of life and activity levels. The current study is part of a longitudinal study of the health and well-being of older adults living in non-institutionalised settings [34]. The dataset gives us the capacity to explore the chronicity and variability of incontinence over time and will be reported in future articles.

\section{Management implications}

UI is a significant health issue in older men and women and is an important risk factor for older people entering residential care [35]. In recent years, there has been a shift in the importance placed on the assessment and management of incontinence in older people. In Australia, the Commonwealth Department of Health and Aged Care has recognised the importance of improving continence management in older people since 1998 (National Continence Management Strategy) [36] and the World Health Organisation Consultation on Incontinence [37] has highlighted the need for management of incontinence through specialist services. The factors that are associated with incontinence in the older person have been well-documented and include mobility problems, medications and alcohol, constipation, diabetes and sensory disability and environmental factors such as the accessibility of a toilet [38]. All these factors are amenable to intervention and specific behavioural therapies such as bladder retraining and pelvic floor exercises have been successful in community dwelling older adults [3]. Behavioural therapy is highly effective ( $80 \%$ cure rate) in clinical trials, but its long-term efficacy in the community setting is unclear [39]. McGhan [15] noted the challenges of managing the condition using antimuscarinic drugs, due to side effects, such as cognitive impairment, tolerability and adherence. Newer forms of drug treatment enable improved efficacy and cost-effectiveness [40]. Intervention studies have shown that quality of life can improve with the proper management of UI [22]. Incontinence can be assisted, if not cured, for most patients.

\section{Methodological considerations}

The interpretation of the findings is limited by the cross-sectional nature of the current data analyses. The data were gathered as part of a comprehensive assessment of the health of older people, rather than as part of a specific study of continence. For that reason, a detailed examination of potential underlying clinical factors associated with self-reported incontinence was not possible.

The MELSHA data are not sufficiently detailed to allow us to assess the quality of management, but given the quality of life findings, effective management regimes are endorsed. Our analyses have shown that the impact on the quality of life and activity of older people is complex: this may have implications for accessing and using available health services. Relatively low rates of seeking of health care for urinary symptoms have been highlighted as a problem in the management of UI $[5,13]$. People may fail to seek help because of the associated stigma or ignorance about available treatments. The BEACH data indicate that, for those aged 65 and over, between $0.1 \%$ and $0.4 \%$ of general practice consultations concern UI [41]. Rates of prescribing were low at 38 per 100 continence problems managed, with referrals being more common. We have shown that impact of UI on self-rated health occurs at a high threshold. The decision to seek services may not be perceived as important until UI significantly affects health status, disability and activity levels. Further, self-management by restricting physical activity may increase the risk of conditions associated with a sedentary lifestyle. Early intervention and appropriate management of urinary symptoms is critical to optimise independence.

Health professionals can no longer accept that UI in old age is a normal part of growing old. Health promotion approaches such as pelvic floor exercises and other general health messages need to be applied 
across the life span in order to prevent and reduce the prevalence of urinary problems later in life. There is a need for targeted health promotion programmes to ensure that older people with urinary symptoms access appropriate health services. We have demonstrated that UI impacts on negative mood at a relatively low threshold of UI. Older people may accept lowered mood as a natural consequence of ageing. We need to encourage older people and health professionals that mood disturbances are important and treatable in older people. General practitioners (GPs) need to be proactive in assessing for possible incontinence in people presenting with depressive symptoms, taking a thorough history, conducting a physical examination and requesting a bladder diary be kept. In most cases, the condition can be simply assessed by the GP and managed using education, pelvic floor exercises and bladder retraining with the support of a specialist physiotherapist or continence therapist [42].

\section{Conclusion}

Many studies have failed to identify the threshold at which UI begins to influence quality of life. Our results show that the threshold at which UI impacted on quality of life varied between different measures of quality of life: quality of life measures that tap negative mood impact at lower levels of urge incontinence. Further, few studies have measured aspects of quality of life that have been identified as salient by older people. In this study, we measured mental health as well as functional effects. Finally, it is important to recognise the influence of gender on the impacts of UI. We need to consider how older men and women judge the impact of UI on various domains of quality of life and integrate these perceptions in our assessment and management strategies.

\section{Acknowledgements}

This article is based on data from the Melbourne Longitudinal Studies on Health Ageing (MELSHA). The MELSHA programme has been funded by a large number of grants and supporting agencies. They include the Victorian Health Promotion Foundation, the National Health and Medical Research Council and the Australian Research Council. The programme is jointly led by Professor Colette Browning from Monash University and Professor Hal Kendig from the University of Sydney and includes collaborators from Sydney, Monash and La Trobe Universities. The baseline data were collected with funding from the Victorian Health Promotion Foundation for the Health Status of
Older People project (Principal Investigators Hal Kendig and Rob Helme). Finally, our sincere thanks are expressed to the older adults who participated in the research through interviews and completion of detailed surveys.

\section{References}

1. Campbell A, Reinken J, McCash L. Incontinence in the elderly: prevalence and prognosis. Age Ageing 1985;14:65-70.

2. Ekelund P, Rundgren A. Urinary incontinence in the elderly with implications for hospital care consumption and social disability. Arch Gerontol Geriatr 1987;6:11-18.

3. Fonda D. Promoting continence as a health issue. Eur Urol 1997;32(Suppl. 2):28-32.

4. Hunskaar S, Vinsnes A. The quality of life in women with urinary incontinence as measured by the sickness impact profile. J Am Geriatr Soc 1991;39:378-382.

5. Roberts RO, Jacobsen SJ, Rhodes T, Reilly WT, Girman CJ, Talley NJ, Lieber MM. Urinary incontinence in a communitybased cohort: Prevalence and healthcare-seeking. J Am Geriatr Soc 1998;46:467-472.

6. Mazzenga L, Bushman W. Male urinary incontinence. In: Ratnaike $\mathrm{R}$, editor. Practical guide to geriatric medicine. Sydney: McGraw-Hill; 2002. pp. 568-581.

7. Wagner $\mathrm{T}, \mathrm{Hu} \mathrm{T}$. Economic costs of urinary incontinence in 1995. Urology 1998;51:355-361.

8. Thom D. Variation in estimates of urinary incontinence prevalence in the community: effects of differences in definition, population characteristics, and study type. J Am Geriatr Soc 1998;46:473-480.

9. Fultz N, Herzog A. Measuring urinary incontinence in surveys. Gerontologist 1993;33:708-713.

10. Nygaard I, Lemke J. Urinary incontinence in rural older women: prevalence, incidence and remission. J Am Geriatr Soc 1996;44:1049-1054.

11. Molander U, Milsom I, Ekelund P, Mellstrom D. An epidemiological study of urinary incontinence and related urogenital symptoms in elderly women. Maturitas 1990; 12:51-60.

12. Burgess A. The silent epidemic. Aust Continence J 1996;4: 4-5.

13. Chiarelli P, Brown W. Leaking urine in Australian women: prevalence and associated conditions. Women Health 1999; 29:1-13.

14. Miller Y, Brown WJ, Russell A, Chiarelli P. Urinary incontinence across the lifespan. Neurourol Urodyn 2003; 22:550-557.

15. McGhan W. Cost effectiveness and quality of life considerations in the treatment of patients with overactive bladder. Am J Manag Care 2001;7:S62-S75.

16. Philp I, Armstrong G, Coyle G, Chadwick I, Machado A. A better way to measure disability in older people. Age Ageing 1998;27:519-522.

17. Aslan E, Beji N, Erkan H, Yalcin O, Gungor F. Urinary incontinence (UI) and quality of life (QoL) of the elderly residing in residential homes in Turkey. Arch Gerontol Geriatr 2009;49:304-310.

18. Pang M, Leung H, Chan L, Yip S. The impact of urinary incontinence on quality of life among women in Hong Kong. Hong Kong Med J 2005;11:158-163.

19. Herzog A, Fultz N, Brock B, Brown M, Diokno A. Urinary incontinence and psychological distress among older adults. Psychol Aging 1988;3:115-121.

20. DuBeau C, Levy B, Mangione C, Resnick N. The impact of urge urinary incontinence on quality of life: Importance of 
patients' perspective and explanatory style. J Am Geriatr Soc 1998;46:683-692.

21. Grimby A, Milsom I, Molander U, Wiklund I, Ekelund P. The influence of urinary incontinence on the quality of life of elderly women. Age Ageing 1993;22:82-89.

22. Fonda D, Woodward M, D'Astoli M, Chin W. Sustained improvement of subjective quality of life in older communitydwelling people after treatment of urinary incontinence. Age Ageing 1995;24:283-286.

23. Ouslander J, Abelson S. Perceptions of urinary incontinence among elderly outpatients. Gerontologist 1990;30:369-372.

24. Wyman J, Harkin S, Choi S, Taylor J, Fantl J. Psychosocial impact of urinary incontinence in women. Obstetr Gynecol 1987;70:378-381.

25. Kendig H, Helme R, Teshuva K, Osborne D, Flicker L, Browning C. Health status of older people project: data report. Melbourne: Victorian Health Promotion Foundation; 1996.

26. Browning C, Kendig H. Cohort profile: The Melbourne longitudinal studies on healthy ageing program. Int $\mathrm{J}$ Epidemiol 2010;e1-e7. Electronic Citation. http://ije.oxfordjournals.org/ content/early/2010/09/03/ije.dyq137.extract. Last accessed 5 September 2010

27. Cornoni-Huntley J, Ostfeld A, Taylor J, Wallace R. Introduction. In: Cornoni-Huntley J, Brock D, Ostfeld A, et al., editors. Established populations for epidemiologic studies of the elderly resource data book. Bethesda, MD: National Institute on Aging, HHS, PHS; 1986. pp. i-iv.

28. Jorm A, Mackinnon A, Henderson S, Scott H, Christensen A, Korten A. The Psychogeriatric Assessment Scales: a multdimentional alternative to categorical diagnosis of dementia and depression in the elderly. Canberra: NHMRC Social Psychiatry Research Unit, The Australian National University; 1993.

29. Lawton P, Kleban MH, Dean J, Rajagopal D, Parmelee P. The factorial generality of brief positive and negative affect measures. J Gerontol 1992;47:228-237.

30. Cox B, Blaxter M, Buckle A, et al. The health and lifestyle survey. Cambridge: Health Promotion Research Trust, University of Cambridge; 1987.
31. Lawton M, Moss M, Fulcomer M, Kleban M. A research and service-oriented multilevel assessment instrument. J Gerontol 1982;37:91-99.

32. Thomas T, Plymat K, Blannin J, Meade T. Prevalence of urinary incontinence. Br Med J 1980;281:1243-1245.

33. Johnson T, Kincade J, Bernard S, Busby-Whitehead J, HertzPicciotto I, DeFriese G. The association of urinary incontinence with poor self-rated health. J Am Geriatr Soc 1998;46: 693-699.

34. Kendig H, Helme R, Teshuva K, Osborne D, Flicker L, Browning C. Health status of older people project: preliminary findings from a survey of the health and lifestyles of older Australians. Melbourne: Victorian Health Promotion Foundation, Lincoln Gerontology Centre - La Trobe University, and National Ageing Research Institute - University of Melbourne; 1996.

35. Baker D, Bice T. The influence of urinary incontinence on publicly financed home care services to low income elderly people. Gerontologist 1995;35:360-369.

36. Commonwealth Department of Health and Aged Care. National continence management strategy. Canberra: Australian Government Publishing Service; 1999.

37. Chancellor MB. Mapping the future for incontinence treatment worldwide: Highlights from the first international consultation on incontinence, 28 June-1 July 1998, Monaco. Rev Urol 1999;1:145-147.

38. National Health and Medical Research Council. Incontinence and the older person. Canberra: Australian Government Publishing Service; 1994.

39. Abrams P, Kelleher C, Kerr L, Rogers RG. Overactive bladder significantly affects quality of life. Am J Manag Care 2000;6:S580-S590.

40. Bentkover J, Chapple C, Corey R, Hill S, Stewart E. Adapting a US cost-offset economic model for overactive bladder for the European marketplace. Value Health 2000;3:361.

41. Charles J, Britt H, Fahridin S. Urinary incontinence in the older patient. Aust Fam Physician 2008;37:105.

42. Santiagu S, Arianayagam M, Wang A, Rashid P. Urinary incontinence:pathophysiology and management outline. Aust Fam Physician 2008;37:106-110. 